\title{
A METHOD OF QUANTITATING INJURY INFLICTED IN ACUTE SPINAL CORD STUDIES ${ }^{1}$
}

\author{
By Herman B. Daniell, Ph.D., W. Wofford Francis, William A. Lee, B.S. and \\ Thomas B. DuCKer, M.D. \\ With Technical Assistance by Roy R. Carson and Mary C. Neale \\ Departments of Pharmacology and Neurosurgery, Medical University of South Carolina, \\ Charleston, S.C., U.S.A.
}

\section{INTRODUCTION}

THE considerable research interest in the pathophyiology and treatment of spinal cord injuries had led to a number of different methods being used to experimentally induce the injury, a subject of a recent review by Dohrmann (1972). As was noted, however, most techniques suffer from the common deficiency of the lack of an accurate means to quantify the extent of the inflicted trauma, as well as from an inability to produce a standardised degree of injury. Currently, two general approaches are most commonly utilised in inducting trauma. The first is principally based upon the work of Tarlov et al. (1953, 1954a, 1954b) and Tator (1973) who induced injury by compression of the cord and the second is based upon the work of Allen (I9II, I9I4). With the latter technique the cord is traumatised by dropping a weight from a known height on the exposed dura and the trauma inflicted is expressed in gram-centimetres (g.-cm.) of force. Although the simplicity of use and the negligible cost for the latter method are strong advantages, the quantitation of the trauma is that of potential force rather than that of delivered force. The present report describes an improved model for the induction of spinal cord injuries in which the force inflicted is highly reproducible and accurately quantifiable.

\section{MATERIALS AND METHODS}

Studies were conducted in adult cats and Rhesus monkeys anaesthetised with sodium pentobarbital $(25 \mathrm{mg} . / \mathrm{kg}$.). Trauma was inflicted in these studies using modifications of the technique originally described by Allen (I9II, I9I4). The modification consisted of the following. The weight, to lessen the effects of friction is dropped down a centre shaft rather than through a cylinder, on to an isometric strain gauge arch assembly which transfers the force to a teflon impounder resting on the exposed dura of the spinal cord. The apparatus shown in Figure I consists of the central shaft and $50 \mathrm{~g}$. weight, an isometric strain gauge arch, and the standard size impounder. The standard size impounder which was used in these experiments is suitable for use in either cats or in monkeys. The impounder is constructed with a concave surface which closely approximates the contour of the cord and the portion of the impounder which rests on the cord has a surface area of $21 \mathrm{~mm}^{2}$. The isometric gauge is constructed by bonding a strain gauge to

1 Supported in part by USPH Grant NS I 10066. 


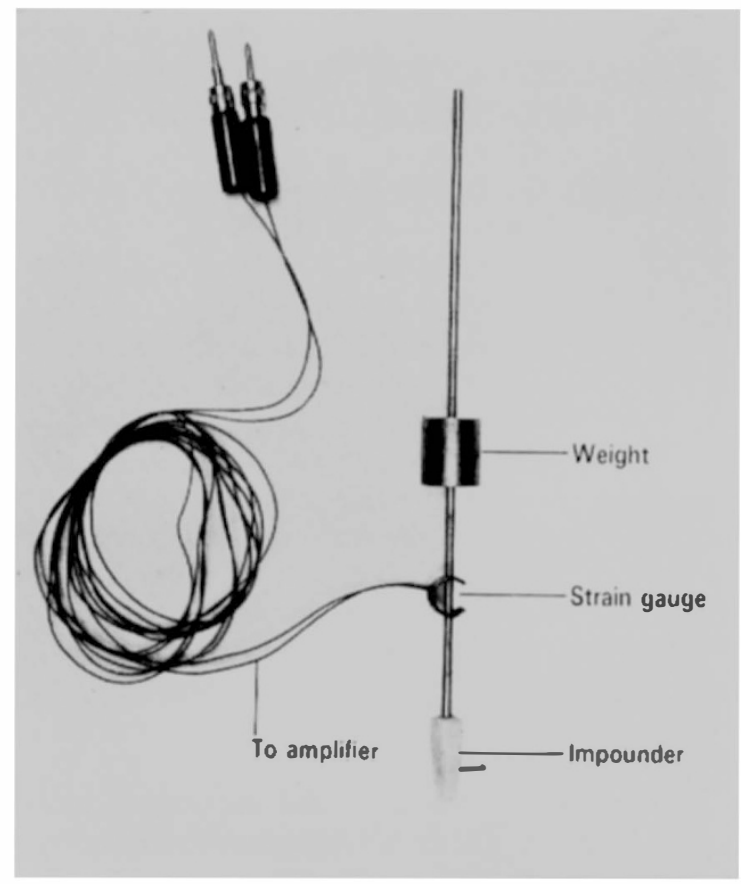

Fig. I

Strain gauge arch assembly for inducing and quantitating spinal cord trauma. The strain gauge and impounder are freely moveable on the centre shaft thus enabling the gauge to remain in contact with the impounder which rests lightly upon the exposed dura of the spinal cord.

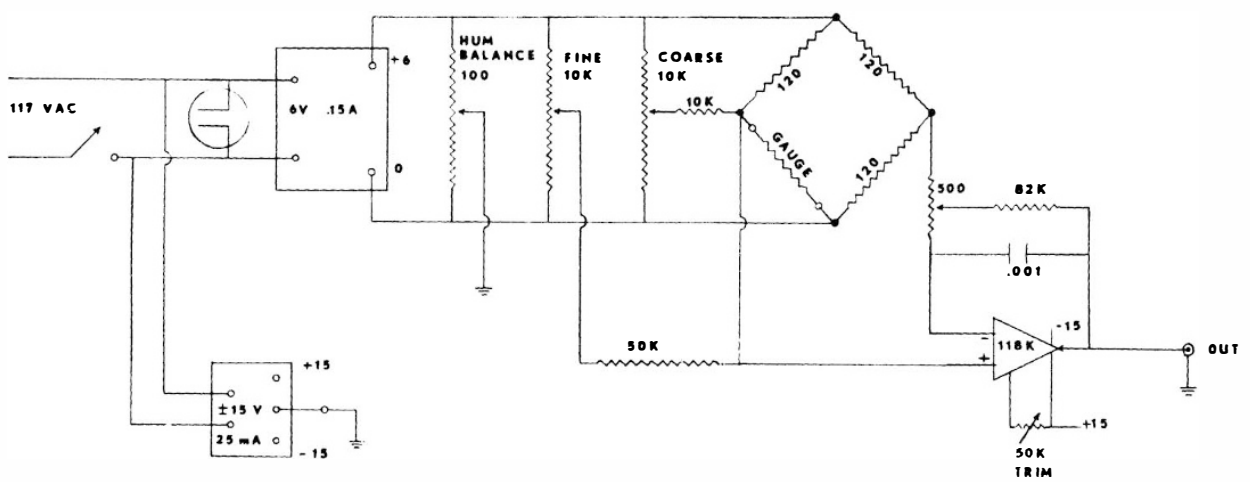

FIG. 2

Circuit diagram of strain gauge arch and balance-amplifier. 


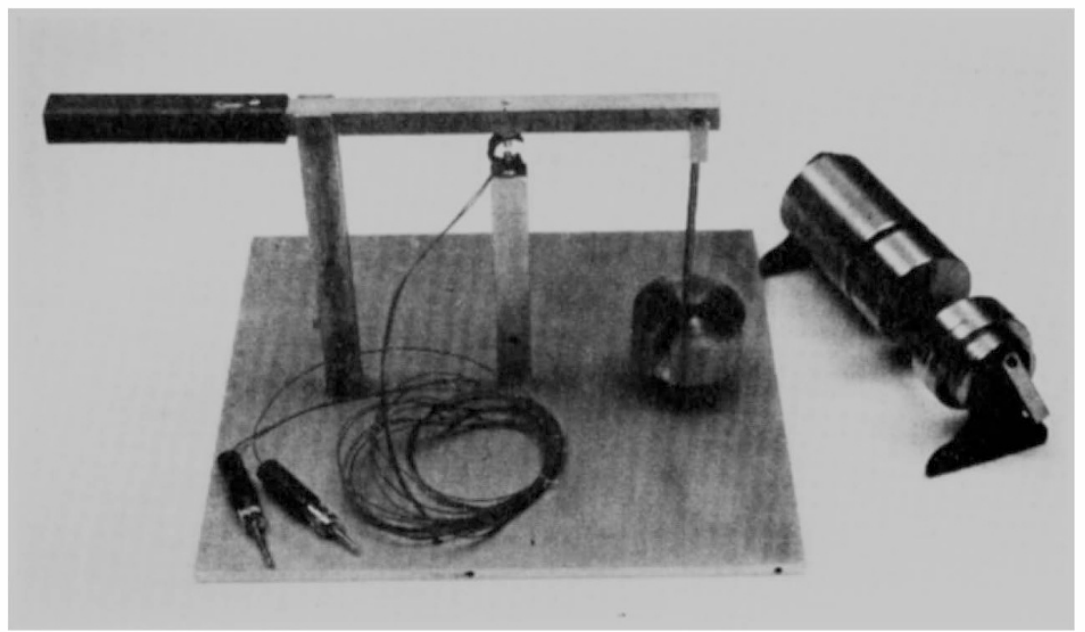

FIG. 3

Strain gauge calibrator. Weights placed on pan exert a force upon the gauge which is amplified, recorded, and quantitated.

a heat treated berrylium copper beam. Signals from the gauge are transferred to a storage oscilloscope through a balance-amplifier (fig. 2) where the force delivered can be displayed, quantitated and photographed for future use.

\section{RESULTS}

By utilising the gauge calibrator as shown in Figure 3, the addition of weights to the suspension pan gives an alteration in the electrical signal which is linear over the range of force commonly used in inflicting experimental spinal cord trauma. This relationship between weight in grams and voltage output from the gauge is shown in Figure 4. Since a weight in grams can be determined which will give an alteration in voltage equal to any force exerted upon the gauge (and therefore to the cord), using such a device, one can express the experimental trauma exerted upon the cord as grams of force that is applied via the standard impounder rather than the potential energy of g.-cm. of force.

Figure 5 shows the relationship between force exerted on the exposed spinal cord of 50 cats and the distance of the weight drops. A typical display of one of these experiments is shown in Figure 6. In preliminary experiments it was found that both the peak force and the configuration of the displayed force curve varied with the mass of the weight, although the calculated g.-cm. force was the same. For example, a $100 \mathrm{~g}$. weight dropped from $5 \mathrm{~cm}$. produced a force curve of less magnitude but greater duration than that produced by a $50 \mathrm{~g}$. weight dropped IO $\mathrm{cm}$.

The method described in this study has now been used to induce experimental spinal cord injury in six anaesthetised Rhesus monkeys. The results of these studies have verified that found in the experiments with cats and indicate that this is a reliable technique for inducing and quantitating spinal cord trauma in either 


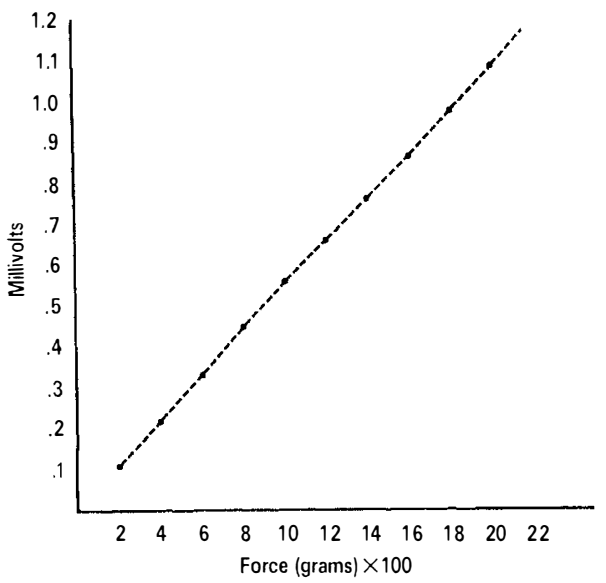

FIG. 4

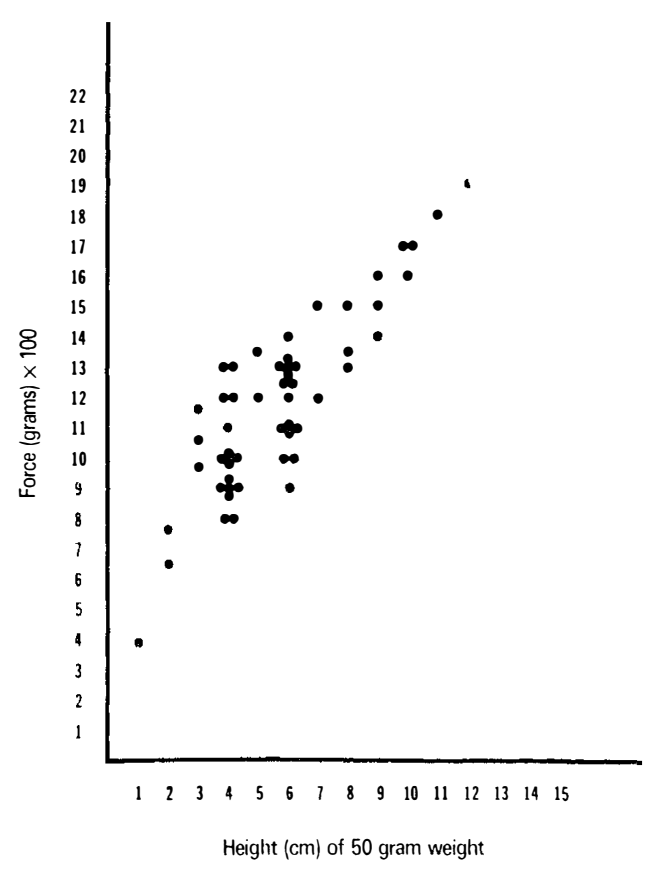

FIG. 5

FIG. 4

Relationship between force exerted on strain gauge arch and voltage output. Each point consists of multiple determinations. (Standard error of the mean $0.003 \mathrm{mV}$ or less at each point.) The relationship between force and voltage output is linear past that force necessary to produce complete paraplegia in cats and monkeys.

FIG. 5

Relationship between the distance of the weight drop and the peak force exerted on the exposed dura of 50 cats. Each point represents a different animal.

species. Although the results from the studies in monkeys are very preliminary, the data suggest that significant neurologic deficit becomes apparent when approximately $500 \mathrm{~g}$. of force are applied to the exposed dura while a force of approximately twice that magnitude is required to produce equal neurologic deficit in cats.

\section{DISCUSSION}

Dohrmann (1972) has indicated the advanta ${ }_{0}$. of using a reproducible and quantifiable form of injury in inflicting experimental spinal cord trauma. The method utilised in these studies has these advantages. Ducker et al. (I97I) have shown that the amount of pathology in the central grey and white matter is directly proportional to the severity of trauma. Therefore it is necessary to accurately quantitate the extent of trauma to make reliable predictions as to the ultimate 


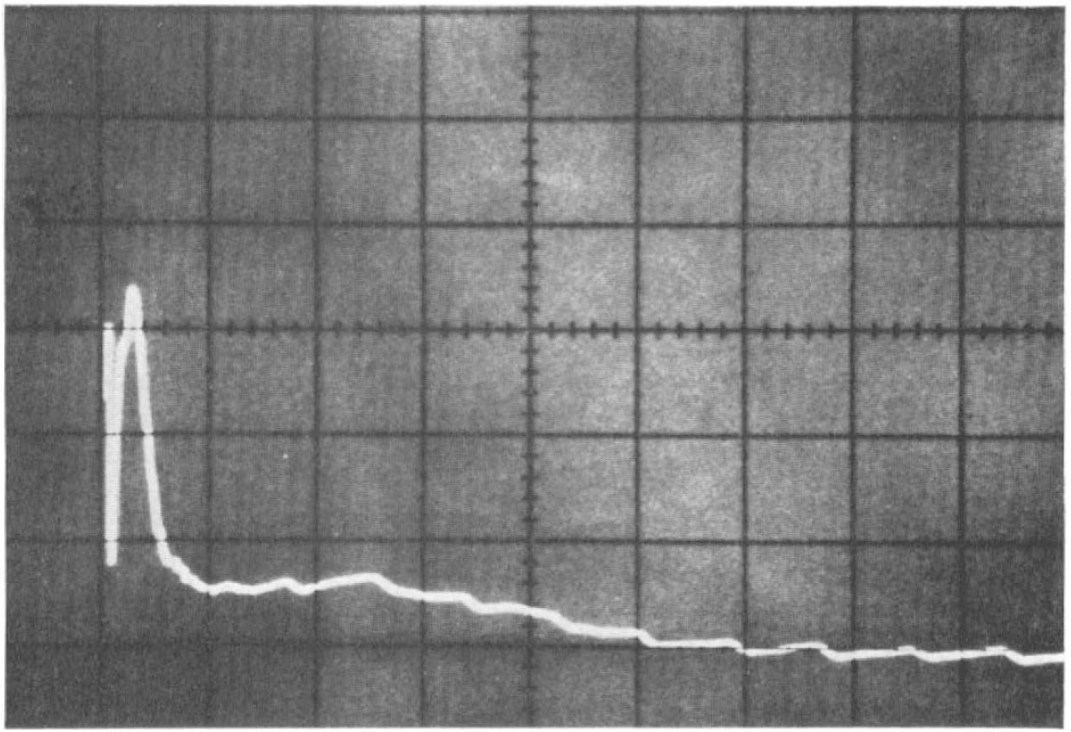

FIG. 6

Oscilloscopic display of force curve in which a $50 \mathrm{~g}$. weight was dropped $9 \mathrm{~cm}$. on the exposed dura of the spinal cord of a cat. The peak force is equivalent to I600 g.

clinical neurologic conditions, a step necessary in the evaluation of therapeutic efficiency.

The data obtained in these studies suggest the need for standardising the weight dropped in inducing experimental spinal cord injuries. Since the dura, subarachnoid space, and cord absorb and dissipate a certain amount of the force due to their cushioning effect and this varies with the mass of the weight employed. It is conceivable that the extent of the pathological lesion produced could be different utilising different weights.

The shape characteristics of the force curve as shown on the oscilloscope are not only dependent upon the mass of the weight and the distance dropped but also upon the recipient material. Soft tissue such as spinal cord will absorb and dissipate the force and give a curve with characteristics shown in Figure 6. Conversely, when the force is delivered to hard tissue such as bone, the strain gauge force curve is one of much higher magnitude but of shorter duration. Since striking bone or failure to deliver the entire force to the spinal cord and its coverings is a significant problem in experimental spinal cord studies, these force curve characteristics can be used to determine when such events occur.

The techniques described in this study lend themselves to an examination of the relationship between trauma exerted and neurologic deficit in several ways. By using the oscilloscopic display of the force curve one can examine not only the relationship between peak force exerted per unit of area and trauma produced but also the relationship between trauma inflicted and the area beneath the force curve. Experimental models in which the effects of potential force on the trauma 
produced are examined must of necessity be relegated to a study of the peak forcetrauma relationship although the latter relationship, i.e. area beneath the force curve may well be the best predictor of the ultimate neurologic deficit.

\section{SUMMARY}

Spinal cord trauma was induced in cats and Rhesus monkeys using an improved method which allows for accurate quantitation of the force delivered. The materials and methods described consist of a weight which is dropped down a centre shaft on to a strain gauge arch assembly which transfers the force to a teflon impounder resting on the exposed dura of the cord. The force transferred from the weight to the impounder is recorded by the strain gauge and the force curve can be displayed on a storage oscilloscope. The force delivered to the cord can thus be photographed and quantitated. The construction of the strain gauge assembly and the application of the apparatus are discussed.

\section{RÉSUMÉ}

Traumatisme du cordon médullaire a été induit sur des chats et des singes Rhésus, en se servant d'une méthode améliorée qui permet un estimé précis de la force delivrée. Les matériaux et méthodes décrits consistent d'un poids qui est laissé tomber dans une manche centre sur un montage vouté de mesure de tension qui transmet la force à un marteau en téflon reposant sur la dura exposée du cordon. La force transférée du poids au marteau est recordée par la mesure de tension et la courbe de force peut être déployée sur un oscilloscope emmagasiné. La force délivrée au cordon peut ainsi être photographiée et sommée. La construction du montage de mesure de tension et l'application de l'appareil sont discutés.

\section{ZUSAMMENFASSUNG}

Experimentelle Rückenmarksverletzungen wurden bei Katzen und Affen mit einer verbesserten Methode ausgeführt, die ein akkurate Bestimmung der Gewalt erlaubt. Die Konstruktion des Appartes und seine Anwendung wird in Einzelheiten beschrieben.

\section{REFERENCES}

AlLEN, A. R. (I9II). Surgery of experimental lesion of spinal cord equivalent to crush injury of fracture dislocation of spinal column. F.A.M.A. 57, 878-880.

Allen, A. R. (I9I4). Remarks on the histopathological changes in the spinal cord due to impact. An experimental study. F. Nerve. Ment. Des. 4I, I4I-I 47.

Dohrmann, G. J. (1972). Experimental spinal cord trauma. Arch. Neurol. 27, 468-473.

Ducker, T. B., KINDT, G. W. \& KEMPE, L. G. (I97I). Pathological findings in acute experimental spinal cord trauma. F. Neurosurg. 35, 700-708.

Tarlov, I. M., Klinger, H. \& Vital, S. (I953). Spinal cord compression studies. I. Experimental techniques to produce acute and gradual compression. Arch. Neural. Psychiat. 70, 813-819.

TARLOV, I. M. \& KLINGER, H. (I954). Spinal cord compression studies. II. Time limit3 for recovery after acute compression in dogs. Arch. Neurol. Psychiat. 7I, 27I-290.

Tarlov, I. M. (I954). Spinal cord compression studies. III. Time limits for recovery after gradual compression in dogs. Arch. Neurol. Psychiat. 7I, 588-597.

TATOR, C. H. (1973). Acute spinal cord injury in primates produced by an inflatable extradural cuff. Can. F. Surg. 16, 222-23I. 